\title{
Inclusão no Ensino Superior: Perceções dos estudantes com Necessidades Educativas Especiais sobre 0 ingresso à universidade
}

\author{
Evelyn Santosi, Manuela Gonçalvesii, Isabel Ramosiii, \\ Lisneti Castroiv \& Roselane Lomeov \\ Universidade de Aveiro, Portugal
}

\begin{abstract}
Resumo
A educação inclusiva no Ensino Superior representa atualmente um desafio de âmbito social, educacional e político, que nos move a uma reflexão sobre o ingresso de estudantes com Necessidades Educativas Especiais (NEE) no Ensino Superior em Portugal. A fim de conhecer os principais suportes referenciados como essenciais para a inclusão optou-se pelo paradigma da investigação interpretativa com cariz qualitativo, sendo a recolha de dados através de entrevista semiestruturada. Foi verificada a importância de vários suportes, em especial o da família. O contingente especial para acesso ao Ensino Superior foi referenciado por todos os estudantes como um importante apoio. A forma como a universidade se organiza na fase de ingresso foi considerada satisfatória; no entanto, apresenta aspetos pontuais a serem modificados. As acessibilidades físicas/estruturais e culturais/atitudinais são citadas como fundamentais para a permanência destes estudantes na Universidade de Aveiro; porém, a falta de respaldo legal e de políticas inclusivas nacionais ainda dificultam esse processo.
\end{abstract}

Palavras-chave

Inclusão; Ensino Superior; Necessidades Educativas Especiais; Ingresso

\section{Introdução}

A problemática da inclusão tem sido cada vez mais abordada. Nos nossos dias torna-se impensável falar em educação sem falar de inclusão, um 
reflexo de políticas emergentes que buscam garantir a escolaridade obrigatória.

Os esforços em prol da construção de uma educação inclusiva têm-se centrado, na maioria dos países, na educação básica. No entanto, o facto de o acesso ao Ensino Superior ser cada vez mais possível para mais jovens, o facto de a formação universitária ser cada vez mais essencial para obter uma formação profissional e emprego, e ainda o facto de as instituições de Ensino Superior integrarem o ensino público, implicam que atualmente se equacione o caráter inclusivo da universidade sobretudo para jovens com Necessidades Educativas Especiais (NEE) (Rodrigues, 2004).

São grandes os desafios num mundo cada vez mais multicultural; no entanto, identificamos esse multiculturalismo como real e essencial sustentáculo da integração social e democrática, tendo consciência e respeito pela diversidade, em particular na escola de nível superior (Barbosa, 2002). Duarte, Rafael, Filgueiras, Neves, e Ferreira (2013) afirmam que pouco se tem investigado sobre a inclusão no Ensino Superior, sendo este um dos fatores que dificultam a formulação de políticas públicas que contemplem ações para uma educação inclusiva também no Ensino Superior.

Dessa preocupação nasceu o desejo de contribuir com a investigação neste campo, bem como de analisar as políticas educativas voltadas a essa problemática. Assim, neste artigo, apresentamos parte de uma investigação mais ampla sobre este tema que conduziu a uma dissertação de mestrado já concluída e defendida, sendo nosso objetivo apresentar e discutir os fatores que constituíram e/ou constituem os principais apoios para o ingresso no Ensino Superior, na ótica dos próprios estudantes com Necessidades Educativas Especiais. O estudo foi realizado com um grupo de 11 estudantes com NEE da Universidade de Aveiro (UA) no ano letivo de 2013/2014.

Segundo dados do Diretório Geral do Ensino Superior (DGES), no ano letivo de 2012/2013, em Portugal, 45.429 estudantes concorreram às vagas existentes para o Ensino Superior. Deste número significativo, 40.415 estudantes foram colocados na primeira fase do concurso nacional de acesso. Concorreram às vagas de contingente especial para estudantes com deficiência 530 estudantes, e destes somente 115 foram colocados. Este número, apesar de relevante, se comparado a anos anteriores, ainda é considerado reduzido. 
Acreditamos que todos os estudantes com NEE têm direito à educação, direito a experimentar e vivenciar aprendizagens e experiências tão diversas, por isso salientamos a importância do acesso/ingresso à universidade. Entendendo o desenvolvimento social como prioridade dentro das políticas públicas e a educação como principal agente transformador, preocupa-nos primeiramente o número significativo de estudantes com NEE que ingressam nas universidades portuguesas. Está disponível um contingente de cerca de $2 \%$ de vagas para este grupo de pessoas e, face aos dados anteriormente apresentados, preocupa-nos só terem entrado no Ensino Superior $0,2 \%$ dos jovens com NEE, apesar de se ter candidatado um número muito superior. Depois, preocupam-nos igualmente as condições que essas universidades disponibilizam, já que incluir não significa simplesmente inserir a pessoa com NEE como mais uma na instituição educacional.

No presente artigo começamos por enquadrar teórica e contextualmente a problemática, em seguida relatamos a metodologia de investigação utilizada e finalmente apresentamos e discutimos os resultados.

\section{Inclusão no Ensino Superior}

O Ensino Superior desempenha um importante papel no desenvolvimento das sociedades, bem como na liderança e nos processos de transformação desta. Entretanto, talvez esse papel nunca tenha sido tão reconhecido como atualmente (Llorent \& Santos, 2012). A Declaração Mundial sobre o Ensino Superior (1998) afirma que a Educação Superior é um dos pilares fundamentais dos direitos humanos, da democracia, do desenvolvimento sustentável e da paz, e que, portanto, deve ser acessível a todos no decorrer da vida. De um lado, a universidade é lócus do conhecimento, sendo da sua competência a produção científica e a articulação com as distintas áreas do saber, mas, de outro, deve ser também o lócus da pluralidade, da diversidade e do respeito às diferenças (Moreira, Bolsanello, \& Seger, 2011).

Todos os seres humanos carregam características comuns e, ao mesmo tempo, possuem as próprias singularidades de desenvolvimento, revelando a sua condição humana. Cada pessoa é diferente pela interação entre o que é, de onde vem e onde está, situação social, ambiente e factos 
atuais (França, 2010). Contrariamente a essa afirmação, percebe-se cada vez mais uma busca pela homogeneização educacional onde regras, práticas e manuais têm a finalidade de abranger a totalidade, padronizando-a, enquadrando tantas diferenças num termo e prática iguais.

A universalização do ensino e o direito à educação para todos são avanços significativos; porém, apesar dessa profunda mudança, a qualificação do ensino tem sido colocada em risco e a massificação é vista como uma problemática cada vez mais percetível. Ao refletirmos sobre a problemática da homogeneização nos contextos educativos e na sociedade, cresce de maior forma o desejo pela abordagem da diversidade e do respeito às diferenças, o que nos motiva a, mais uma vez, enfatizarmos a importância da inclusão.

O número de estudantes com NEE no Ensino Superior tem aumentado gradualmente nas últimas duas décadas, devido à implementação de medidas políticas e sociais de acesso e democratização que promovem a inclusão educativa neste nível de ensino (Faria, 2012). A universidade entrelaça-se com a inclusão, ela convida-nos a pensar na e para a inclusão. Os sistemas educativos que apresentam níveis de excelência são os que mais vivenciam e investem na inclusão, pois a inclusão desassossega a universidade. Confrontamo-nos, pois, com uma temática emergente que necessita de ser discutida para além da educação básica e secundária, para que, assim, estudantes com NEE ingressem no Ensino Superior, tendo a oportunidade de concluir mais um percurso na trajetória estudantil.

Castanho e Freitas (2005) ressaltam que os contextos educacionais onde os estudantes são incluídos são responsáveis pela promoção de cidadania e, para tal, propiciam e incentivam a educação para todos, configurando-se a universidade como um espaço de construção e trocas de conhecimento, além do convívio social. A universidade pode considerar o significado da sua função social no sentido de que as pessoas com NEE deixem de ser representadas pelas categorias de ineficiência, de desvio, do atípico e do improdutivo, e a elas sejam assegurados os direitos à igualdade de oportunidades e à educação (Moreira, 2005).

O princípio da educação inclusiva requer das instituições escolares o reconhecimento e o encaminhamento de práticas que respondam às necessidades educacionais, por meio de uma educação que garanta às 
pessoas com NEE o atendimento de acordo com as suas especificidades (Garcia, Rodriguero, \& Mori, 2011).A efetiva inclusão de estudantes com NEE no Ensino Superior deve-se à atenção à trajetória escolar dos estudantes como parte fundamental no processo que se compõe do acesso, ingresso, permanência e saída. Tendo em conta o caminho percorrido por cada um desses atores sociais, bem como o significado que lhe atribuem, entende-se que a permanência na universidade implica um trabalho constante.

O processo de inclusão é determinado pela interação entre as variáveis individuais e as variáveis do meio. Ninguém é aceite só pelas suas capacidades individuais nem contra elas, só pelas características do meio, nem contra as características do meio. É, pois, um processo interativo e dinâmico, resultante da influência de múltiplos fatores (Rodrigues, 2004). Ao reconhecermos a inclusão como um processo global, entendemos que potencializar o investimento em políticas educacionais, a fim de que estas invistam em espaços inclusivos, no desporto, lazer, inclusão no mercado de trabalho, escolas, universidades, dentre outras mudanças que o setor social tem vindo a promover, é essencial e urgente, para desenvolver o potencial e respeitar as necessidades e diferenças de cada indivíduo.

O conceito de escola inclusiva está relacionado com a modificação da estrutura, do funcionamento e da resposta educativa, de modo a que se tenha lugar para todas as diferenças, quer sejam individuais, sociais ou culturais, inclusive aquelas que estão associadas a alguma deficiência (Guijarro, 1998). Percebe-se cada vez mais a necessidade de atender à inclusão como uma totalidade na diversidade, para que os quatro pilares propostos pela Organização das Nações Unidas para a Educação, a Ciência e a Cultura (UNESCO) para a educação - aprender a conhecer, aprender a fazer, aprender a conviver e aprender a ser - possam constituir realidade e prática pedagógica.

As últimas décadas foram marcadas por movimentos importantes para a educação especial e inclusiva, sendo pautadas por debates, reflexões e investigação no âmbito da educação básica. Segundo Rodrigues (2004), atualmente estamos a incidir sobre a inclusão no Ensino Superior, como reflexo dos avanços na escolarização que se foram verificando nos diferentes graus de ensino. As principais práticas voltadas ao Ensino Superior apontam para estratégias multifacetadas e globais, envolvendo todos os atores deste 
processo: docentes, estudantes, currículos, instituições e contextos de aprendizagem (Watzlawick, 2011), pois a aprendizagem influencia o seu contexto e é influenciada por ele.

\section{Ingresso ao Ensino Superior}

Cada vez mais instituições de Ensino Superior têm apresentado medidas para a inclusão de estudantes com NEE, a começar pelo ingresso destes à universidade. Conforme refere Rodrigues (2004), o ingresso é um dos campos onde se tem verificado maior evolução atualmente.

De acordo com a UNESCO (1998), é necessário desenvolver uma política ativa de facilitação do acesso ao Ensino Superior para os membros de certos grupos especiais, tais como os povos indígenas, as minorias culturais ou linguísticas, os grupos sociais desfavorecidos, os povos sob ocupação e as pessoas com deficiência, dado que esses grupos, tanto como pessoas coletivas como em termos individuais, podem ser detentores de experiências e talentos de grande valor para o desenvolvimento das sociedades e nações. A elaboração de materiais especiais de apoio e de soluções educativas específicas pode ajudar a ultrapassar os obstáculos que tais grupos enfrentam, tanto no que respeita ao acesso como à continuação de estudos de nível superior.

A palavra 'acesso' pode trazer embutida a ideia de sair de um determinado lugar ou situação e ir para um lugar ou situação diferente do/da anterior. Esse lugar ou situação pode referir-se a um espaço físico ou a uma situação que reflete status social - por exemplo, ter acesso ao Ensino Superior (Watzlawick, 2011). Noutra perspetiva, mais lata e abrangente, entendemos por acesso o conjunto de possibilidades específicas que permitem ao estudante com NEE frequentar e relacionar-se com a comunidade académica (Rodrigues, 2004).

Percebe-se que a barreira do acesso/ingresso ao Ensino Superior tem vindo a ser ultrapassada, apesar da necessidade de muitos avanços, principalmente no que diz respeito à informação sobre as diferentes formas de candidatura às universidades e às condições especiais para as provas de acesso. Medidas como a ampliação do tempo para eventuais provas de ingresso, intérpretes de língua gestual, salas adaptadas, vagas de 
estacionamento nas proximidades, equipamentos adequados para os universitários - quer sejam eles portadores de deficiência física, visual, auditiva ou deficiências múltiplas -, entre outras, enquadram as condições especiais para a realização dos exames nacionais aos estudantes com NEE do Ensino Secundário (Ministério da Educação e Ciência, 2013).

É notório o crescente número de estudantes com NEE que ingressa no Ensino Superior nos últimos anos, mas ainda temos uma população muito reduzida se compararmos com os números gerais dos estudantes que entram na universidade. Para Garcia, Rodriguero, e Mori (2011), estes resultados são resquícios da segregação, da extinção e da discriminação sofridas pelas pessoas com NEE ao longo da história. Percebe-se que o paradoxo da inclusão e da exclusão dos sistemas educacionais universalizaram o acesso, mas a exclusão sucede-se para pessoas e grupos que não se enquadram nos 'padrões de homogeneização' estabelecidos por esse sistema educacional (Garcia, Rodriguero, \& Mori, 2011).

\section{Metodologia}

Este estudo, de cariz qualitativo, centra-se no paradigma da investigação interpretativa (Amado, 2013), buscando a compreensão das intenções e significações, crenças, opiniões, perceções, representações, perspetivas e conceções que os seres humanos colocam nas suas próprias ações, na relação com os outros e com os contextos em que e com que interagem. Procura-se o que faz sentido na realidade e como faz sentido para os sujeitos investigados, os fenómenos tal como são percebidos e manifestos pela linguagem, investigando sem isolar os contextos natural, histórico, socioeconómico e cultural em que se desenvolvem, à procura da compreensão (Amado, 2013, p. 40).

\section{Objetivos}

Esta investigação teve dois objetivos fundamentais:

1) Conhecer o percurso pré-universitário de estudantes com NEE, visando a identificação e a compreensão dos fatores pessoais, educativos e socioculturais que tornaram o seu acesso possível. Pretendemos, portanto: caraterizar o percurso pré-universitário 
destes estudantes; identificar quais foram os suportes essenciais no percurso pré-universitário; e descrever o processo e as escolhas referentes ao ingresso na universidade.

2) Identificar, através das perceções dos estudantes universitários com NEE, os fatores organizacionais e políticos utilizados pela instituição de Ensino Superior para atender às suas especificidades. Aqui buscamos: especificar os fatores identificados como essenciais para a permanência no Ensino Superior; descrever como são percebidos os fatores organizacionais da UA pelos estudantes com NEE; e elencar as políticas nacionais e/ou específicas da UA referentes à inclusão no Ensino Superior.

\section{Participantes}

As especificidades do grupo participante são apresentadas no Quadro 1 e os critérios para a escolha dos participantes foram considerados de acordo com as seguintes características: diversidade de ciclos e anos letivos do percurso académico; diversificação de departamentos e de cursos; diferentes NEE; número equilibrado de estudantes de cada género. Procurase a diversidade e não a homogeneidade, e, para garantir que a investigação aborda a realidade considerando as variações necessárias, é preciso assegurar a presença da diversidade dos sujeitos ou das situações em estudo (Guerra, 2006).

\section{Técnicas de recolha e análise dos dados}

Objetivando conhecer o percurso universitário de estudantes com NEE e visando a identificação e compreensão dos fatores pessoais, educativos e socioculturais que tornaram possível o seu acesso à universidade, bem como descrever o processo e as escolhas referentes ao ingresso, realizámos entrevistas semiestruturadas a 11 estudantes da UA, no ano letivo de 20132014, sendo 6 do sexo feminino e 5 do sexo masculino.

O guião de entrevista adotado foi construído a partir dos objetivos da pesquisa e da análise prévia a estudos voltados para a inclusão no Ensino Superior. Com base nesta análise, foram construídas perguntas referentes às seguintes dimensões, estipuladas como essenciais na trajetória dos 
estudantes universitários: I) Caracterização pessoal e sociodemográfica; II) Percurso pré-universitário; III) Acesso à universidade; e IV) Permanência.

Quadro 1 - Caracterização dos estudantes entrevistados

\begin{tabular}{|c|c|c|c|}
\hline Género & Idade & Ciclo/Curso & NEE \\
\hline $\mathrm{F}$ & 50 anos & Mestrado em Tradução & $\begin{array}{l}\text { Acidente Vascular Cerebral } \\
\text { com comprometimento motor }\end{array}$ \\
\hline $\mathrm{F}$ & 26 anos & $\begin{array}{l}\text { Mestrado em Psicologia } \\
\text { Clínica }\end{array}$ & Baixa visão com perda gradual \\
\hline $\mathrm{F}$ & 19 anos & Licenciatura em Tradução & Paralisia cerebral e Dislepsia \\
\hline M & 19 anos & $\begin{array}{l}\text { Licenciatura em Engenharia } \\
\text { Eletrónica e } \\
\text { Telecomunicações }\end{array}$ & Daltonismo \\
\hline M & 23 anos & Mestrado em Música & Invisual \\
\hline $\mathrm{F}$ & 26 anos & $\begin{array}{l}\text { Programa doutoral em } \\
\text { Multimédia em Educação }\end{array}$ & $\begin{array}{l}\text { Paralisia cerebral com } \\
\text { comprometimento motor }\end{array}$ \\
\hline M & 25 anos & Licenciatura em Fisioterapia & Baixa visão \\
\hline $\mathrm{F}$ & 24 anos & Licenciatura em Bioquímica & Espinha bífida (cadeirante) \\
\hline M & 21 anos & $\begin{array}{l}\text { Licenciatura em Engenharia } \\
\text { Mecânica }\end{array}$ & Dislexia \\
\hline M & 23 anos & Licenciatura em Física & Dislexia \\
\hline $\mathrm{F}$ & 22 anos & $\begin{array}{l}\text { Mestrado em Biomedicina } \\
\text { Farmacêutica }\end{array}$ & Osteogénese Imperfeita \\
\hline
\end{tabular}

As entrevistas foram realizadas nos espaços da UA, em ambiente reservado; apenas uma foi realizada via Skype, tendo a duração média de uma hora. Foram registadas com o apoio de um gravador, após o consentimento de todos os entrevistados.

A análise dos discursos produzidos foi norteada pelo prisma da análise de conteúdo de Bardin (2006). Num primeiro momento, a partir da leitura inicial dos conteúdos, organizámos as dimensões, desenhadas pelos objetivos traçados através da entrevista semiestruturada, na qual as categorias e subcategorias emergiram; estas categorias emergiram, não só do guião e da consulta prévia às investigações internacionais, mas também da própria fala dos entrevistados. 
260 Evelyn Santos et al.

A credibilidade da investigação realizada deve-se a exaustiva análise, sendo que fomos igualmente apoiados pelo software de análise qualitativa WebQDA, para auxílio quanto ao rigor e qualidade da análise dos textos, a fim de que fossem corretamente codificadas as categorias e subcategorias. Esse software auxiliou-nos com maior versatilidade, permitindo-nos criar, codificar, editar, organizar documentos e questionar os dados de forma a responder aos nossos objetivos. No quadro 2 pode-se visualizar um esboço das categorias e subcategorias emergentes na dimensão 'Ingresso à UA'.

Quadro 2 - Apresentação das categorias e subcategorias da dimensão Ingresso na UA

\begin{tabular}{|c|c|c|}
\hline Dimensão & Categoria & Subcategoria \\
\hline \multirow{5}{*}{ 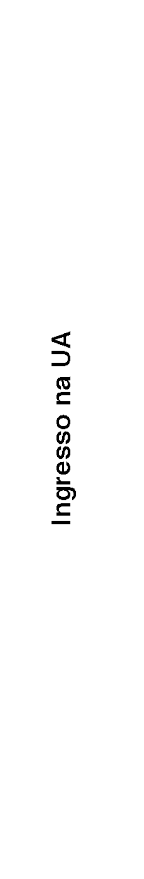 } & Escolha da Universidade & $\begin{array}{l}\text { - Localização } \\
\text { - Excelência académica } \\
\text { - Ser inclusiva } \\
\text { - Sem pré-requisitos } \\
\text { - Cursos oferecidos }\end{array}$ \\
\hline & $\begin{array}{l}\text { Seleção por contingente } \\
\text { especial }\end{array}$ & $\begin{array}{l}\text { - Importante } \\
\text { - Não importante }\end{array}$ \\
\hline & $\begin{array}{l}\text { Maior(es) incentivo(s) para o } \\
\text { ingresso no Ensino Superior }\end{array}$ & $\begin{array}{l}\text { - Família } \\
\text { - Própria vontade } \\
\text { - Antigos professores } \\
\text { - Instituição que acolhe } \\
\text { - Médico que acompanha }\end{array}$ \\
\hline & $\begin{array}{l}\text { Suporte social aos estudantes } \\
\text { no ingresso }\end{array}$ & $\begin{array}{l}\text { - Satisfatório } \\
\text { - Insatisfatório }\end{array}$ \\
\hline & $\begin{array}{l}\text { Informação aos professores } \\
\text { sobre as NEE dos estudantes }\end{array}$ & $\begin{array}{l}\text { - Conhecimento prévio } \\
\text { - Sem conhecimento prévio }\end{array}$ \\
\hline
\end{tabular}




\section{Apresentação dos resultados}

Não havendo legislação a nível nacional no âmbito do apoio aos estudantes com NEE, a UA foi construindo procedimentos de apoio caso a caso. A estrutura referenciada aos estudantes da UA que apresentam NEE chama-se Gabinete Pedagógico. Este gabinete não se dedica exclusivamente ao atendimento a estudantes com NEE, encontrando-se disponível em igualdade de circunstâncias para todos os estudantes da Universidade de Aveiro; porém, tem centrado a sua atenção na criação de estratégias a fim de possibilitar ações que promovem a inclusão dos estudantes, tais como: intercâmbio com o Ensino Secundário; ingresso/acolhimento; organização para a acessibilidade no campus; ações de voluntariado; adaptação nas avaliações; projetos sociais.

Após o estudo sobre os recursos que a UA oferece, sentimos a necessidade de ouvir as perceções dos estudantes quanto ao conhecimento e satisfação sobre esses recursos no seu percurso universitário e perceber quais são os fatores inibidores e facilitares da inclusão na fase de ingresso ao Ensino Superior.

\section{Ingresso ao Ensino Superior}

A escolha da universidade faz parte do imaginário de muitos estudantes que idealizam o acesso ao Ensino Superior. Quer seja por escolha própria ou incentivo de outrem, essa opção é obviamente importante. Para os estudantes entrevistados, os principais motivos para a escolha da UA correspondem à excelência académica, através de 8 unidades de texto, conforme explicitado pela opinião do/a estudante AP: "Tenho conhecimento que a Universidade de Aveiro tem qualidade a nível de ensino, então pronto, essa foi uma das principais razões". O facto de ser inclusiva foi também referenciado em 8 unidades de texto, e AS exemplifica-o ao dizer: "Eu vim estudar pr'aqui e ainda bem que vim porque a UA é uma das melhores universidades a nível de acessibilidade de materiais, a universidade tem um bom serviço de documentação que nos coloca o material acessível".

Relativamente à prova de acesso com que concorreram à universidade, foram questionados sobre se tinham conhecimento do contingente especial e se consideravam que esse era importante. Nenhum 
estudante expressou não ser importante ou pouco importante. Todos os 11 estudantes tinham conhecimento do contingente especial; porém, explicitaram em quatro momentos a preocupação com a falta de informação relativamente a esse recurso - IG relata-nos que: "Às vezes há muita falta de informação sobre os apoios que existem para os cidadãos com NEE. Acho que há falta de informação". Contudo, nenhum estudante expressou não ser importante ou pouco importante; unanimemente referiram ser um grande apoio para o acesso ao Ensino Superior. Com efeito, reforçamos que o contingente é um dos principais apoios ao ingresso de estudantes com NEE no Ensino Superior, e conforme ressalva AS na sua entrevista:

Nós temos várias limitações, nós precisamos de mais tempo para fazer as coisas, mais tempo... É assim: se eu não tivesse o contingente especial, eu certamente... a probabilidade de eu ficar aqui era relativamente significativa, mas imagina que eu não ficava aqui e tinha que estudar, sei lá, p'ro Algarve ou sei lá... É assim: eu acho que o contingente especial serve, eu acho que, de uma certa forma, é uma boa ideia para dar oportunidade às pessoas com NEE.

\section{Número ainda reduzido de estudantes com NEE}

Os estudantes entrevistados foram questionados quanto aos motivos do número ainda reduzido de estudantes com NEE no Ensino Superior e verificou-se que, segundo as suas perceções, esse facto deve-se em primeiro lugar ao receio dos estudantes. Para AA, um fator impeditivo "é o receio da rejeição, do medo de não conseguir, de achar que é demasiado difícil, difícil em termos de se adaptar, de acharem que se calhar não conseguem, que é complicado, que é... Acho que é mais isso, o desconhecimento, o medo e o receio". Ao longo da vida foram tão estigmatizados que um dos reflexos dessa realidade é a dificuldade em perceber que têm possibilidades e capacidades. Essas reações são percetíveis na fala dos entrevistados e exemplificadas pela fala de IG:

Eu dizia à minha mãe: "Ó mãe, eu sei que não tenho possibilidades de me manter numa universidade, mas eu gostava de ir p'ra universidade, nem que seja um ano, para ver como é que é, como é o ambiente, como são as pessoas, como é que... como é que... como é a vida académica.

O segundo motivo do número ainda reduzido de estudantes com NEE no Ensino Superior apontado pelos estudantes refere-se à falta de informação. São apresentadas 10 unidades de texto nas quais referem, como 
AP, que "a informação relativamente ao facto de esses alunos, essas pessoas com NEE poderem ter acesso ao Ensino Superior ainda está muito pouco divulgada".

Além da falta de informação, as dificuldades relacionadas com as questões financeiras são também referenciadas pelos estudantes, conforme descreve SM: "É claro, às vezes a componente financeira também é, porque, quer queiramos quer não, uma pessoa que tenha alguma limitação...as famílias dessa pessoa ou dessa criança têm que sempre gastar mais algum dinheiro extra p'ra completar essa limitação...". Através dos dados apresentados, entende-se que a questão financeira é considerada um dos principais motivos para o número ainda reduzido de estudantes que ingressam no Ensino Superior, podendo isso ser comprovado através do número escasso de auxílios financeiros recebidos pelos estudantes. De entre os 11 estudantes entrevistados, 7 não recebem bolsa de estudo e somente 4 recebem algum tipo de auxílio; segundo AM: "Pagar quase 200 euros por cada prestação de propinas não é fácil, pagar mais um tanto por alojamento e depois, por exemplo, gastar mais 50 euros como muitas vezes eu gasto por mês em medicamentos, não é fácil".

A falta de apoio, quer seja por parte da família (8), da escola (7) ou de forma geral (7), foi também referenciada como um dos motivos para um número ainda reduzido de estudantes com NEE no Ensino Superior. Para SM,

(...) o mais importante ainda é preparar o aluno desde o primeiro ano para entrar na universidade e não começar a pensar no aluno: "Ah, ele tem uma limitação ou X ou Y, enfim, e nunca vai dar p'ra vir para a universidade". É claro que não, não é. Essa mentalidade é que não... é que às vezes não deixa os alunos progredirem mais; é a falta de apoio no ensino básico, no ensino secundário.

Além dos fatores já descritos até aqui, o preconceito foi também evidenciado. Para AS, "Ainda há muito a ideia de que uma pessoa com deficiência não tem que ter, por exemplo, de que um cego não consegue ser professor, não consegue ser psicólogo, não consegue ser... percebes?, um cego só serve para ser telefonista e pronto".

\section{Maior incentivo para o ingresso no Ensino Superior}

O maior incentivo para o ingresso no Ensino Superior foi referenciado pelos estudantes, através de 9 unidades de texto, como sendo o da família: 
"Mais uma vez foram os meus pais, me incentivaram muito", relata MS. Em segundo lugar, o incentivo está relacionado com a própria vontade, o que pode perceber-se em 7 referências e como descreve SM: "Por incrivel que pareça, foi o meu próprio orgulho, eu simplesmente decidi". Os antigos professores também têm um importante papel no incentivo ao ingresso no Ensino Superior e foram referenciados 5 vezes durante as entrevistas. $O$ suporte familiar e o incentivo de que todos temos capacidades são essenciais para a conquista de objetivos, conforme expressa um dos entrevistados:

(...) o que me caracteriza é a minha força de vontade, nunca ter desistido dos meus objetivos. Porque também sempre tive a família que me apoiou, isso também é muito importante, que por vezes há famílias com crianças com NE que não valorizam as competências que aquela criança obteve. E por vezes até olham só para as incapacidades, e não para as competências...

\section{Suporte da universidade no ingresso dos estudantes com NEE}

Quando questionados os estudantes sobre o suporte da UA na fase de acesso, averiguamos se o suporte social foi satisfatório ou insatisfatório e percebemos que, na sua perspetiva, a UA organiza-se e disponibiliza um suporte social satisfatório aos estudantes. Segundo eles, os principais motivos são: informações, com 16 unidades de texto, e apresentação dos recursos, referida em 14 unidades de texto e descrita por AS:

Eu sei os recursos que a universidade tem e se eu posso utilizá-los. No momento que eu estava a fazer a minha matrícula, disseram-me: "Olha, antes de se ir embora, é importante que vocês falem com a responsável do gabinete pedagógico, porque como esta aluna tem $\mathrm{NE}$, ela não vê, é preciso ter alguns cuidados, e dado que vocês estão cá hoje, ela pode-os receber.

Apesar de o maior número de referências ser de satisfação, apresentamos seguidamente os aspetos descritos pelos estudantes como insatisfatórios. É interessante perceber que são os mesmos fatores referidos como satisfatórios, porém de forma menos positiva. Foram então evidenciados dois aspetos: a falta de informação, descrita em 11 unidades de texto, e a falta de apresentação dos recursos, em 6 referências, sendo esta lacunas apresentadas como fator gerador de maior dificuldade no ingresso, conforme salienta RP: "A minha sorte é que já tinha cá um irmão e também tinha alguns amigos cá, que eu entrei aqui e eles disseram que eu tinha que fazer isso". 
Conforme os dados anteriormente apresentados, os estudantes afirmam que a UA possibilita um suporte social satisfatório referente ao acesso à universidade. Apesar disso, ainda existem situações preocupantes, referenciadas principalmente no que diz respeito à falta de informação, que necessitam ser sanadas, o que, segundo Ferreira (2007), é de suma importância, pois o acompanhamento do estudante inicia-se por um momento de acolhimento, para lhe assegurar que não é um mero número na universidade e ouvir as suas solicitações quanto ao apoio institucional.

\section{Considerações finais}

O ingresso de estudantes com NEE no Ensino Superior tem vindo a ser uma realidade cada vez mais presente, e esse número acrescido tem impulsionado as organizações políticas e instituições a oferecer recursos; porém, esse acesso ainda não é percebido por todos como sendo para todos. Percebe-se, em todo o caso, que a barreira do acesso ao Ensino Superior tem vindo a ser ultrapassada aos poucos, apesar da necessidade de muitos avanços, principalmente no que diz respeito à informação sobre as diferentes formas de candidatura às universidades e às condições especiais para as provas de acesso.

A nível político, um dos principais recursos mencionados tem sido o acesso pelo contingente especial e, ao nível institucional, as acessibilidades, presentes desde o momento do ingresso na universidade e durante $o$ percurso académico. Apesar de o ingresso/acesso ao Ensino Superior ser um dos aspetos mais referenciados e em que se investe na área da inclusão, atualmente, ainda há muito a ser feito e considerado de forma a dar conhecimento sobre as oportunidades que os estudantes com NEE têm, os seus direitos, os apoios oferecidos, bem como a investir em políticas e financiamento para os estudos aos estudantes que apresentam maiores dificuldades financeiras, podendo ser este um dos fatores impeditivos para 0 ingresso e permanência no Ensino Superior.

Com efeito, por um lado, compreender as dificuldades e expectativas da pessoa com deficiência é fundamental; contudo, noutra perspetiva, e tal como afirma AS: "Nós temos que nos fazer ouvir e nós temos que ser persistentes, fazer com que as pessoas satisfaçam as nossas necessidades, 
porque se nós não dissermos que precisamos de uma coisa, a pessoa não vai adivinhar". Evidencia-se, pois, a necessidade de ser organizado um sistema de informações facilmente acessível aos estudantes com NEE, mas também a necessidade do conhecimento prévio dessas necessidades por parte da instituição como um todo e, mais especificadamente, por parte dos docentes. Tanto a necessidade de conhecer os apoios oferecidos pela universidade como a necessidade de conhecimento prévio são fatores fundamentais para a adaptação destes estudantes ao Ensino Superior, Deve ter-se em atenção que tal adaptação, bem como o desempenho e os sentimentos por eles experienciados, dependem também da forma como são acolhidos pela instituição (Abreu, 2013). De entre todas as estratégias apresentadas, salientamos a importância do suporte das políticas educativas e o reflexo da não existência de medidas sistemáticas e legais nas universidades. Poderíamos afirmar que a retórica é tendente à valorização da inclusão dos estudantes com NEE, os estudantes reconhecem e valorizam o papel desempenhado pelas estruturas e agentes de apoio, relevando de maneira especial o constante e importante papel da coordenadora do Gabinete Pedagógico no apoio individualizado, através de medidas avulsas e pontuais que visam a inclusão destes alunos na UA. Existem sobretudo iniciativas que necessitam de ser afirmadas de uma forma mais clara e sistemática, a fim de assegurar as suas práticas numa regulação legalmente explícita.

Conclui-se referindo que o intuito destas reflexões não é propriamente o de apontar o que está bem ou os aspetos que necessitam de mudanças, mas antes dar a conhecer as condições satisfatórias para que os estudantes possam aprimorar-se no que lhes é oferecido e, principalmente, apontar as necessidades presentes para que essas sejam conhecidas, a fim de serem superadas e sanadas, bem como apresentar a realidade da inclusão no Ensino Superior como algo acessível a todos, para que outras famílias e futuros universitários percebam que existem desafios, sim, mas que também existe inclusão.

As principais limitações implicadas na pesquisa foram as relacionadas com o tempo e com o consentimento dos participantes. A conclusão de uma pesquisa desta extensão é um desafio e, portanto, algumas alterações tiveram que ser pensadas e realizadas para que a falta de tempo não prejudicasse a condução do trabalho. A pesquisa, que visava atentar também 
na perceção do corpo docente, juntamente com o discente, passou a englobar somente a perceção dos estudantes e a análise documental, que acreditamos terem sido igualmente ricas em dados e correspondentes aos nossos objetivos.

Outro aspeto a referir foi a adesão dos alunos ao estudo. Idealizámos um número um pouco maior de participantes, mas principalmente que englobasse maior diversidade de NEE. Contudo, além da dificuldade em contactar e de organizarmos as entrevistas conforme a disponibilidade de muitos deles, percebemos que um grande número de estudantes não se sente à vontade para falar sobre as suas limitações e tem receio da participação, mostrando-se inseguros também quanto à incerteza do seu anonimato, mesmo esse sendo referido e assegurado.

É da realidade da UA que surge mais uma preocupação: a necessidade de suporte aos estudantes surdos, NEE que não é encontrada na universidade e que o Gabinete Pedagógico relata não ter condições para receber.

Refletindo sobre possíveis implicações e objetivos de estudo futuro, notamos a necessidade de uma pesquisa que faça o cruzamento dos dados de forma mais global, o que, conforme referido acima, não foi possível tendo em conta os constrangimentos temporais. Será importante cruzar os dados referentes às perceções dos estudantes e a perceção dos docentes, bem como os desafios que eles enfrentam.

Em síntese, notamos que há ainda muito a ser investigado na área da educação inclusiva no Ensino Superior e, apesar das limitações e de projetarmos algumas implicações futuras, concluímos esta investigação certos de que muito aprendemos e queremos compartilhar.

\section{Referências}

Abreu, S. (2013). Alunos com Necessidades Educativas Especiais: Estudo exploratório sobre a inclusão no Ensino Superior (Dissertação de mestrado não publicada). Universidade da Madeira, Portugal.

Amado, J. (2013). Manual de investigação qualitativa em educação. Coimbra: Imprensa da Universidade de Coimbra. 
Barbosa, M. M. (2002). A inclusão e a diversidade no Ensino Superior. Revista Educação \& Mudança, 9/10, 2-16.

Bardin, L. (2006). Análise de conteúdo. Lisboa: Edições 70.

Castanho, D., \& Freitas, S. (2005). Inclusão e prática docente no Ensino Superior. Revista do Centro de Educação, 27, 93-99.

Duarte, E., Rafael, C., Filgueiras, J., Neves, C., \& Ferreira, M. (2013). Estudo de caso sobre a inclusão de alunos com deficiência no Ensino Superior. Revista Brasileira de Educação Especial, 19(2), 289-300.

Faria, C. (2012). Inclusão de alunos com Necessidades Educativas Especiais no Ensino Superior: Estudo exploratório sobre a percepção dos docentes (Dissertação de mestrado não publicada). Universidade da Madeira, Portugal.

Ferreira, S. (2007). Ingresso, permanência e competência: Uma realidade possível para universitários com Necessidades Educacionais Especiais. Revista Brasileira de Educação Especial, 13(1), 43-60.

França, R. (2010). A inclusão sob o olhar do professor: Um estudo de representação social. Retirado de: http://www.portalanpedsul.com.br/admin/uploads/2002/ Gestao_e_politicas_educacionais/Poster/01_11_10_p425.pdf

Garcia, D., Rodriguero, C., \& Mori, N. (2011). Inclusão no Ensino Superior: O olhar do aluno. In Atas do VII Encontro da Associação Brasileira de Pesquisadores em Educação Especial (pp. 574-583). Londrina: UEL.

Guerra, J. (2006). Que perspectivas para o século XXI?. In Atas do I Congresso de Educação do Algarve (pp. 12-19). Faro: Universidade do Algarve.

Guijarro, R. (1998). Aprendendo en la diversidad: Implicaciones educativas. In Atas do III Congresso Ibero-Americano de Educação Especial (pp. 33-17). Foz do Iguaçu, PR.

Llorent, V., \& Santos, M. (2012). Legislação educacional e inclusão na Universidade Federal do Rio de Janeiro (Brasil) e na Universidade de Córdoba (Espanha). Revista Galego-Portuguesa de Psicoloxía e Educación, 20(1), 7-24.

Moreira, L. (2005). In(ex)clusão na universidade: O aluno com Necessidades Educacionais Especiais em questão. Revista do Centro de Educação, 25, 1-6.

Moreira, L., Bolsanello. M., \& Seger, R. (2011). Ingresso e permanência na universidade: Alunos com deficiências em foco. Educar em Revista, 41, 125143.

Rodrigues, D. (2004). A inclusão na universidade: Limites e possibilidades da construção de uma universidade inclusiva. Revista do Centro de Educação, 23, 22-26.

UNESCO (1998). Declaración Mundial sobre la Educación Superior en el siglo XXI. Visión y Acción. Conferencia Mundial sobre la Educación Superior, París, 5-9 oct.

Watzlawick, J. (2011). As (im)possibilidades da inclusão na Educação Superior (Dissertação de Mestrado não publicada). Universidade Federal de Santa Maria, Brasil. 


\title{
Legislação consultada
}

Ministério da Educação e Ciência. (2013). Aplicação de condições especiais na realização das provas e exames do ensino básico e do ensino secundário: Orientações Gerais 2013, alunos com Necessidades Educativas Especiais. Júri Nacional de Exames. Governo de Portugal.

\section{INCLUSION IN HIGHER EDUCATION: PERCEPTIONS OF STUDENTS WITH SPECIAL EDUCATIONAL NEEDS ON ENTRANCE TO UNIVERSITY}

\begin{abstract}
Nowadays inclusive education in Higher Education is considered to be a challenge in social, educational and political domains, that moves us towards a reflection regarding the entrance of students with Special Educational Needs in the Portuguese Higher Education sector. To obtain knowledge about the main support considered to be important in inclusion, the investigation was conducted according to a qualitative method, collecting data through a semistructured interview. This data concludes that support measures are extremely important, especially the family. The Special Contingency to access the Higher Education was considered by students as an important support. The University's organization in the entrance process was considered to be satisfactory, which justifies why some aspects need to be modified. Despite the fact that inclusive politics in Portugal difficult the process of permanency of these students in the University of Aveiro, the physical, structural, cultural and attitudinal accessibilities are pointed as fundamental elements in their permanency.
\end{abstract}

Keywords

Inclusion; Higher Education; Special Educational Needs; Entrance 


\section{INCLUSIÓN EN LA EDUCACIÓN SUPERIOR: LAS PERCEPCIONES DE LOS ALUMNOS CON NECESIDADES EDUCATIVAS ESPECIALES EN EL INGRESO A LA UNIVERSIDAD}

\section{Resumen}

La educación inclusiva en la Educación Superior representa, en la actualidad, un desafío de carácter social, educacional y político, lo que nos mueve para una reflexión acerca del ingreso de los estudiantes con Necesidades Educativas Especiales en la Educación Superior en Portugal. Para conocer los suportes principales referidos como esenciales para la inclusión hemos optado por una investigación cualitativa, recogiéndose los datos a través de una entrevista semiestructurada. La importancia de los varios suportes fue comprobada, especialmente de la familia. El contingente especial para el acceso a la Educación Superior fue referido por los estudiantes como un importante apoyo. La organización de la universidad en la fase del ingreso fue considerada satisfactoria, aunque presente algunos aspectos que deben ser cambiados. Las accesibilidades físicas/estructurales y culturales/actitudinales son consideradas como fundamentales para la permanencia de estos estudiantes en la Universidad de Aveiro, aunque la ausencia de políticas inclusivas nacionales dificulte muchísimo ese proceso.

Palabras-clave

Inclusión; Educación Superior; Necesidades Educativas Especiales; Ingreso

Recebido em junho/2015

Aceite para publicação em outubro/2015

\footnotetext{
Departamento de Educação, Universidade de Aveiro, Portugal.

Departamento de Educação, Universidade de Aveiro, Portugal.

Departamento de Educação, Universidade de Aveiro, Portugal.

Departamento de Educação, Universidade de Aveiro, Portugal.

v Departamento de Educação, Universidade de Aveiro, Portugal.
}

Toda a correspondência relativa a este artigo deve ser enviada para: Evelyn Michelini Fortes dos Santos, Universidade de Aveiro, Departamento de Educação, Campus Universitário de Santiago, 3810-193 Aveiro. E-mail: evelynsantos@ua.pt 